\title{
Modulation of the Impacts of the Indian Ocean Basin Mode on Tropical Cyclones over the Northwest Pacific during the Boreal Summer by La Niña Modoki
}

\author{
JINGLIANG HUANGFU \\ Center for Monsoon System Research, Institute of Atmospheric Physics, Chinese Academy of Sciences, Beijing, China \\ Wen CHEN AND Ronghui HuAng \\ Center for Monsoon System Research, Institute of Atmospheric Physics, Chinese Academy of Sciences, and College of \\ Earth and Planetary Sciences, University of Chinese Academy of Sciences, and State Key Laboratory of Numerical \\ Modeling for Atmospheric Sciences and Geophysical Fluid Dynamics, Institute of Atmospheric Physics, \\ Chinese Academy of Sciences, Beijing, China \\ JUAN FENG \\ Center for Monsoon System Research, Institute of Atmospheric Physics, Chinese Academy of Sciences, Beijing, China
}

(Manuscript received 26 September 2018, in final form 8 March 2019)

\begin{abstract}
This paper investigates how La Niña Modoki modulates the impacts of the warm Indian Ocean basin mode (IOBM) on the boreal summer climate and the genesis of tropical cyclones (TCs) over the northwest Pacific (NWP). The results showed that the influence of the Indian Ocean sea surface temperature (SST) on TC genesis is the primary mechanism during the boreal summer, while La Niña Modoki exerts a secondary influence. However, although the summertime index of the IOBM shows a high negative correlation with the number of TCs generated over the NWP, warm IOBM events without La Niña Modoki have only limited influences on the boreal summertime circulations and TC genesis. The present study showed that when warm IOBM events and La Niña Modoki coexisted, the average location of TC genesis shifted westward, and the annual number of generated TCs substantially decreased. La Niña Modoki-related cold sea surface temperature anomalies over the central Pacific further suppressed convective activities over the eastern NWP compared with warm IOBM events without La Niña Modoki. Upper-level convergence and enlarged tropospheric vertical wind shears both contributed to the weakening of the low-level relative vorticity in the coupled cases, leading to a suppressed NWP monsoon trough. Additionally, together with the weaker moisture supply, the impacts of warm IOBM cases were significantly enhanced under the modulation of La Niña Modoki, leading to poorer TC genesis conditions over the eastern NWP. In addition, the energy conversion processes in the aforementioned modulation showed that joint cases will provide fewer initial disturbance seedlings for TC genesis. These results are useful for further understanding the role of warm IOBM cases in TC genesis over the NWP.
\end{abstract}

\section{Introduction}

El Niño-Southern Oscillation (ENSO) events have a significant influence on the climate throughout East Asia (Huang and Wu 1989; Wang et al. 2000; Huang et al. 2004; Li and Zhou 2012; Ha et al. 2013a,b). Wang et al. (2000) suggested that an anomalous lower-level anticyclone (cyclone) located over the Philippine Sea represents a key system connecting El Niño (La Niña)

Corresponding author: Dr. Jingliang Huangfu, hfjl@mail.iap.ac.cn events with the East Asian winter monsoon. Additionally, they also noticed that ENSO-related anomalies can persist only until the following early summer at the latest. When entering the boreal summer [hereafter defined as June-August (JJA)], the sea surface temperature anomaly (SSTA) over the tropical Indian Ocean (TIO) becomes a more important factor with prolonged ENSO effects on the summer climate over East Asia and the northwest Pacific (NWP) (Xie et al. 2009). TIO warming induces a baroclinic Kelvin wave into the Pacific that can maintain the anomalous 
anticyclone. Based on these studies, Du et al. (2011) suggested that El Niño-induced TIO warming causes a decrease in tropical cyclone (TC) activities in JJA over the NWP. Zhan et al. (2011a,b) emphasized the robust impact of the east Indian Ocean (EIO) SSTAs, showing that they affect TC genesis over the entire NWP and largely determine the number of both the total and weak TCs. Ha et al. (2015) further examined the contribution of EIO SSTAs to TC activity under different ENSO phases.

The prolonged ENSO effect mentioned above is known as the "capacitor effect," because the TIO in the region of $40^{\circ}-100^{\circ} \mathrm{E}$ and $20^{\circ} \mathrm{S}-20^{\circ} \mathrm{N}$ becomes charged similar to a capacitor (Xie et al. 2009). This broad area over the TIO is usually uniform at the basin scale, and its dominant mode is referred to as the Indian Ocean basin mode (IOBM) (Klein et al. 1999). The IOBM is the first leading empirical orthogonal function (EOF1) SSTA pattern and accounts for approximately $40 \%$ of the total variation of Indian Ocean SSTAs (not shown). The IOBM shows a distinctive influence on the East Asian monsoon climate (Yuan et al. 2008a,b; Zhan et al. 2011a; B. Wu et al. 2012; $\mathrm{Ha}$ et al. 2015). Warm IOBM events usually follow El Niño events (Wu et al. 2010). Yuan et al. (2008a) suggested that warm IOBM events prolong ENSO effects by modifying the anomalous anticyclone over the western Pacific. The IOBM can largely influence the interannual variability in the genesis of TCs during the peak TC season over the NWP (Yu et al. 2016). The number of total TCs (especially weak TCs) over the NWP decreases during warm IOBM years (Tao et al. 2012). The work of Tao et al. (2012) is consistent with that of Zhan et al. (2011a) based on an extended time period of the basin mode, that is, the IOBM. Zhan et al. (2014) suggested that the areal coverage of the EIO SSTA expanded westward after the late 1970s (Figs. 4e and $4 \mathrm{f}$ in Zhan et al. 2014). These results may suggest that the signal of the IOBM is enhanced interdecadally.

In recent decades, ENSO Modoki events have occurred with greater frequency, and they are typically characterized by SSTAs over the central Pacific (CP) that are quite different from conventional ENSO events (Ashok et al. 2007). According to Ashok et al. (2007), the amplitude of El Niño Modoki reaches its peak during the boreal winter. However, El Niño Modoki events decay too rapidly, and thus, compared with conventional El Niño events, they exhibit a different influence on the East Asian climate via a distinct physical mechanism (Feng et al. 2011). The impacts of El Niño Modoki on the summer climate are focused during its developing phases (Yuan and Yang 2012;
Feng and Chen 2014). Weng et al. (2011) investigated the influences of conventional El Niño and El Niño Modoki in addition to the Indian Ocean dipole on the summer climate in China, and they concluded that El Niño Modoki exhibits the strongest relationship with the NWP summer monsoon. Recently, other researchers have focused on the cold phase of ENSO Modoki, that is, La Niña Modoki, which significantly differs from conventional La Niña events and shows a different influence on the East Asian climate (Cai and Cowan 2009; Wang et al. 2012; Karori et al. 2013; Ding et al. 2017). Zhang et al. (2015) showed the necessity to separate La Niña Modoki from the conventional events because its climate impacts are different. Frauen et al. (2014) investigated the nonlinearity of ENSO teleconnections and suggested that most strong La Niña are CP events. Song et al. (2017) reported the impacts of La Niña Modoki on Australian summer rainfall: they suggested that the SSTAs during La Niña Modoki events can induce an anomalous anticyclone, bringing additional moisture to northeastern Australia and leading to greater precipitation. This anomalous anticyclone may also influence the summertime climate over the NWP and thus TC genesis.

In addition, Zhan et al. (2014) showed that the impact of the westward extension of EIO SSTAs on TC genesis over the NWP is largely suppressed in recent decades. Thus, although the signal of the IOBM is enhanced, its influence is weakened. Therefore, investigating whether La Niña Modoki can modulate the effect of the IOBM on TCs over the NWP during the boreal summer and enhance its influence is of interest. Accordingly, we investigate the dynamic processes associated with the modulation of La Niña Modoki on the IOBM-related genesis of NWP TCs.

The remainder of this study is structured as follows. The data and methods are described in section 2, and the relationships between the genesis of NWP TCs and the indices of the IOBM and ENSO Modoki are presented in section 3. The modulation of the IOBM and TC genesis by La Niña Modoki is examined in section 4, following which the impacts of La Niña Modoki on the changes in TC-related thermodynamic variables and energy conversions are investigated in section 5. Finally, the results are discussed and summarized in section 6 .

\section{Data and methods}

\section{a. Data}

JJA TC data during 1979-2016 are obtained from the International Best Track Archive for Climate Stewardship (IBTrACS) (Knapp et al. 2010). The TCs are counted and identified as originating over the NWP 
$\left(110^{\circ} \mathrm{E}-180^{\circ}, 0^{\circ}-40^{\circ} \mathrm{N}\right)$ when the storm reaches a tropical depression intensity. The location of each genesis is identified as the location where a TC was first recorded. The IBTrACS dataset collects data from four agencies (Joint Typhoon Warning Center; the China Meteorological Administration-Shanghai Typhoon Institute; the Regional Specialized Meteorological Center Tokyo, and the Hong Kong Observatory) and retains nameless TCs with short life cycles. Therefore, the counts may differ when analyzing each dataset from the aforementioned agencies. All TCs generated over the NWP should be considered in the present study; therefore, we employed the IBTrACS dataset. The present version of the data is v03r10, and its resolution is $1^{\circ} \times 1^{\circ}$.

We employed daily and monthly ERA-Interim reanalysis data, including wind and relative humidity data, at a resolution of $2.5^{\circ} \times 2.5^{\circ}$ during 1979-2016 (Simmons et al. 2007). Outgoing longwave radiation (OLR) data during 1979-2013 and uninterpolated daily mean data during $2014-16$ with a $2.5^{\circ} \times 2.5^{\circ}$ resolution are obtained from the National Oceanic and Atmospheric Administration (NOAA) archives (Liebmann and Smith 1996). The uninterpolated data are interpolated into the same format as the OLR data. Monthly SST data during 19792016 with a resolution of $1^{\circ} \times 1^{\circ}$ are obtained from the Met Office Hadley Centre's sea ice and SST monthly mean datasets (Rayner et al. 2003).

\section{b. Methods}

Following Xie et al. (2009), the index of the IOBM is calculated by the averaged SSTAs over the TIO $\left(40^{\circ}-\right.$ $\left.100^{\circ} \mathrm{E}, 20^{\circ} \mathrm{S}-20^{\circ} \mathrm{N}\right)$. We chose a threshold of 0.5 standard deviation to ensure that each group (warm, cold, and normal IOBM events) comprised approximately one-third of the samples over the studied period (38 years). In addition, because the IOBM is more influential on the interannual variability in the genesis of TCs during the peak TC season over the NWP, we remove the least squares linear trend of the IOBM index to eliminate its long-term variability. Therefore, a warm IOBM case is selected when the detrended IOBM index is greater than 0.5. Accordingly, eight warm IOBM cases $(1983,1987,1988,1991$, 1998, 2003, 2010, and 2015) are identified. To examine whether the warm IOBM events were well selected, we further employed EOF to check the dominant spatial pattern (EOF1) and the first leading principal component (PC1) of the SSTAs over a region defined by $40^{\circ}-120^{\circ} \mathrm{E}, 20^{\circ} \mathrm{S}-20^{\circ} \mathrm{N}$ (not shown). Following Saji et al. (1999), this region exhibits both the IOBM and IOD mode. The correlation coefficient between the time series of the IOBM index and PC1 is 0.976 .
Therefore, the warm IOBM events selected based on the area-averaged SSTAs are reliable.

According to Ashok et al. (2007), the ENSO Modoki index (EMI) is calculated as follows:

$$
\mathrm{EMI}=[\mathrm{SSTA}]_{\mathrm{A}}-0.5 \times[\mathrm{SSTA}]_{\mathrm{B}}-0.5 \times[\mathrm{SSTA}]_{\mathrm{C}} .
$$

In Eq. (1), [SSTA] refers to the area-averaged SSTAs, and the subscripts $\mathrm{A}, \mathrm{B}$, and $\mathrm{C}$ denote the tropical $\mathrm{CP}\left(165^{\circ} \mathrm{E}-140^{\circ} \mathrm{W}, 10^{\circ} \mathrm{S}-10^{\circ} \mathrm{N}\right)$, eastern Pacific $\left(110^{\circ}-\right.$ $\left.70^{\circ} \mathrm{W}, 15^{\circ} \mathrm{S}-5^{\circ} \mathrm{N}\right)$, and western Pacific $\left(125^{\circ}-145^{\circ} \mathrm{E}\right.$, $10^{\circ} \mathrm{S}-20^{\circ} \mathrm{N}$ ), respectively. Following Feng et al. (2017), we identify a La Niña Modoki case when the normalized summer mean EMI is less than -0.8. All La Niña Modoki mentioned in this study refer to its developing phases. Thus, five La Niña Modoki cases (1983, 1989, 1998, 2008, and 2010) are identified. Considering that a large percentage of warm IOBM cases coexist with La Niña Modoki cases, the warm IOBM events are divided into two groups: the warm IOBM with La Niña Modoki (IOBM-LNM) cases $(1983,1998$, and 2010) and the warm IOBM without La Niña Modoki (IOBM-no LNM) cases $(1987,1988$, 1991, 2003, and 2015).

Correlation analysis is applied to derive the relationship between the genesis of NWP TCs in JJA and the indices of the IOBM and ENSO Modoki. To highlight their interannual relationships, we remove all of their linear trends. Then, composite analysis based on the aforementioned groups is performed to illustrate the dynamic processes of the modulation of the IOBMrelated atmospheric circulation anomalies by La Niña Modoki, the changes in the associated environmental factors, and the barotropic eddy energy conversions. Student's $t$ test is employed to examine the significance of both the correlation coefficients and the composite anomalies.

\section{The role of La Niña Modoki in the relationship between the genesis of NWP TCs and the IOBM during the boreal summer}

The role of La Niña Modoki in the relationship between the IOBM and the genesis of NWP TCs in JJA is investigated in this section. As shown in Fig. 1, the index of the IOBM, the EMI, and the number of generated NWP TCs in JJA are normalized by a standard deviation of their interannual anomalies. Additionally, we remove all of their linear trends while retaining their interannual components. The number of generated NWP TCs in JJA shows a significant negative correlation with the index of the IOBM (correlation coefficient: -0.57), suggesting 


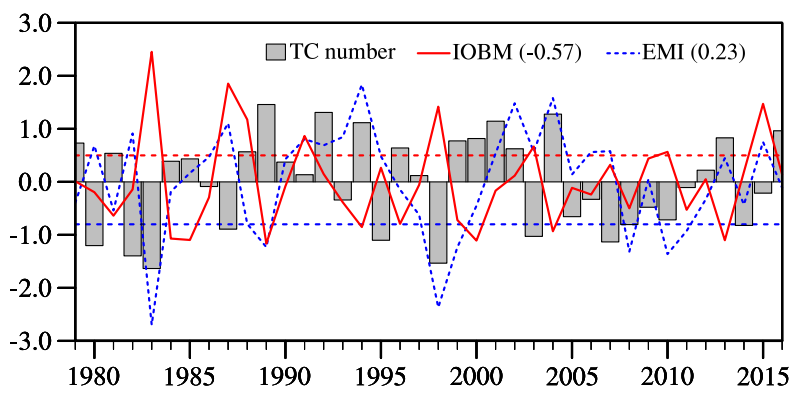

FIG. 1. Time series of the number of generated TCs over the NWP in boreal summer during 1979-2016 (bar graph). The solid red curve represents the normalized index of the IOBM, and the blue dashed curve represents the EMI during the same period.

that the IOBM is the main dominant mode affecting TC genesis during JJA. When warm (cold) IOBM cases occur, TC genesis in the NWP tends to be suppressed (enhanced). In addition, we analyze the interannual variations in the EMI and calculate its correlation with the number of generated TCs in JJA: the results show that the generated number of TCs has a weaker positive correlation (0.23) with the summer mean EMI. This result is somewhat different from that inferred in the work of Chen and Tam (2010), who showed that the TC frequency is significantly positively correlated with the ENSO Modoki index (0.36) in the boreal summer (JJA). The discrepancy between these results and those of the present study might result from the different analysis periods [1960-2008 in the work by Chen and Tam (2010) and 1979-2016 in this study] and the different selected regions $\left[120^{\circ} \mathrm{E}-180^{\circ}, 0^{\circ}-30^{\circ} \mathrm{N}\right.$ in $C h e n$ and Tam (2010) and $110^{\circ} \mathrm{E}-180^{\circ}, 0^{\circ}-40^{\circ} \mathrm{N}$ in this study]. However, note that several warm IOBM years happen to coincide with La Niña Modoki cases. Therefore, whether La Niña Modoki can modulate the relationship between the IOBM and the genesis of NWP TCs must be determined.

Figure 2 shows the composite summer mean SSTAs during the IOBM-no LNM and IOBM-LNM cases. In the cases of the IOBM-no LNM, scattered warm SSTAs are observed in the northwestern TIO, with cold SSTAs observed in the southeastern TIO. We ignore these differences, considering their small coverage and limited amplitudes. Significant warm SSTAs are observed in the central TIO; however, no significant SSTA signals are observed in the tropical and subtropical Pacific. This group is mainly influenced by the warm IOBM SSTA pattern. However, in the cases of the IOBM-LNM, La Niña Modoki SSTAs can be observed in the tropical Pacific coincident with significant cold SSTAs covering the CP stretching westward
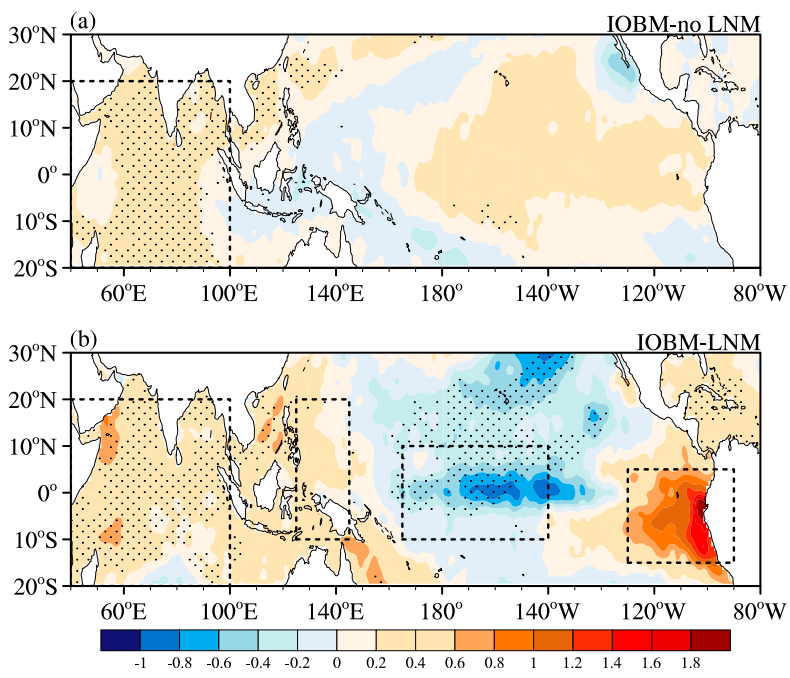

FIG. 2. Composite summer (JJA) mean SST anomalies (shading; ${ }^{\circ} \mathrm{C}$ ) for the (a) IOBM-no LNM and (b) IOBM-LNM. The dashed black boxes denote the key SST regions for the IOBM and ENSO Modoki. Stippling denotes anomalies significant at the $90 \%$ confidence level according to the Student's $t$ test

to the longitude of $150^{\circ} \mathrm{E}$. The amplitudes of the warm SSTAs in the TIO in these two groups are comparable. Hence, it is reasonable to divide the warm IOBM cases into two groups. In this study, we compare the differences between these two groups to reveal the potential modulation of the warm IOBM by La Niña Modoki and its impacts on the genesis of TCs.

\section{The modulation of the IOBM by La Niña Modoki and its impacts on the genesis of TCs}

As shown in Fig. 3a, during the IOBM-no LNM cases, the convection over the tropical NWP (represented by OLR) were suppressed, especially the regions to the west of $140^{\circ} \mathrm{E}$. Correspondingly, significant anomalous anticyclonic $850 \mathrm{hPa}$ winds were observed over the South China Sea (SCS) and the western part of the NWP. The annual number of generated TCs is approximately 12.6 , which is slightly less than the climatological summer mean (14.1). The locations of these generated TCs are scattered. When the warm IOBM cases coexist with La Niña Modoki, as shown in Fig. 3b, much weaker convections are shifted southward. Moreover, the anticyclonic wind anomalies are significantly strengthened, with a larger coverage and greater wind speed. These wind anomalies can reflect the weakening of the monsoon trough (MT), which influences the genesis of TCs (Huangfu et al. 2017a,b,c, 2018). The average locations are shown in Figs. $3 \mathrm{a}$ and $3 \mathrm{~b}\left(15.4^{\circ} \mathrm{N}, 143.9^{\circ} \mathrm{E}\right.$ in the IOBM-no LNM cases and $15.3^{\circ} \mathrm{N}, 132.5^{\circ} \mathrm{E}$ in the IOBM-LNM 

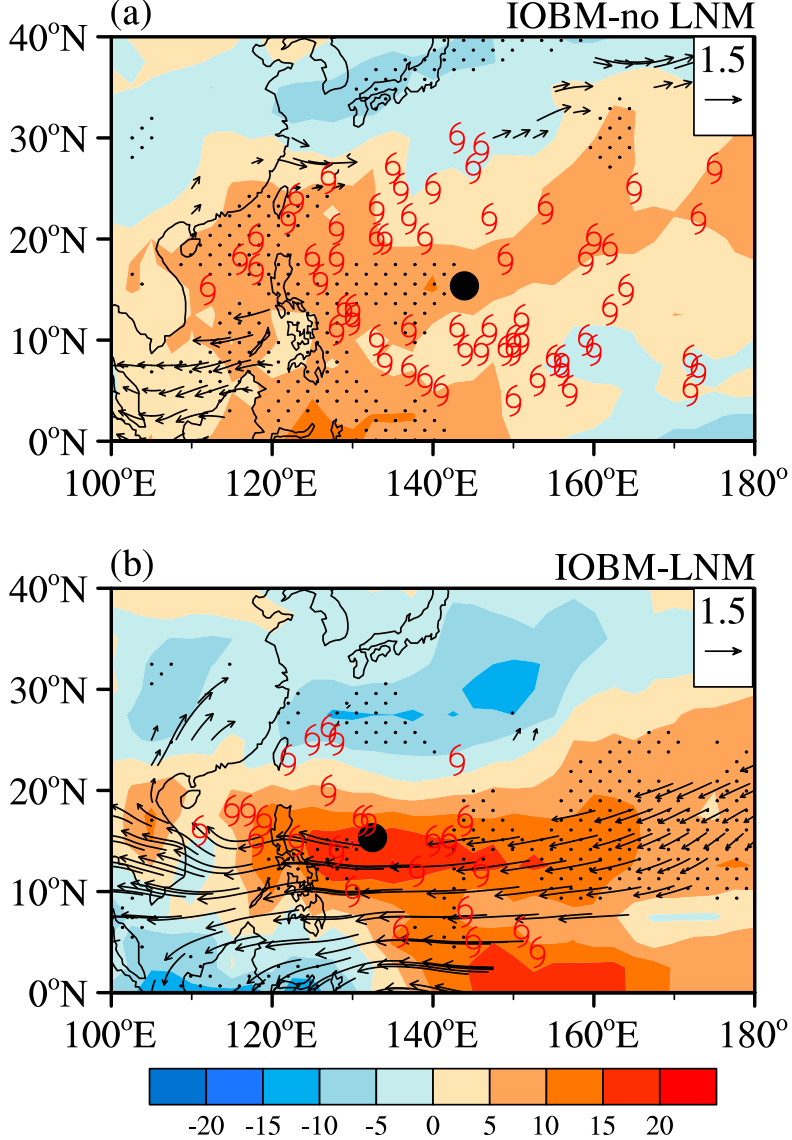

FIG. 3. Composite summer (JJA) mean 850-hPa horizontal wind field (vectors; $\mathrm{m} \mathrm{s}^{-1}$ ) and OLR (shading; $\mathrm{W} \mathrm{m}^{-2}$ ) anomalies for the (a) IOBM-no LNM and (b) IOBM-LNM. The typhoon symbols indicate the locations of generated TCs. The black dots in (a) and (b) indicate the average locations of TCs. The vectors and stippling denote anomalies significant at the $90 \%$ confidence level according to the Student's $t$ test.

cases). Compared with the IOBM-no LNM cases (Fig. 3a), the average longitudes of the generated TCs in the IOBM-LNM cases (Fig. 3b) shifted westward by approximately $11.4^{\circ}$, and the annual number of generated TCs fell to 9. Thus, we note that the weakening effect of the IOBM-no LNM cases on the genesis of TCs is limited, while the joint effect with $\mathrm{La}$ Niña Modoki is powerful.

In this section, we investigate the large-scale atmospheric circulation anomalies. The northern extent of the Walker circulation averaged between the latitudes of $0^{\circ}$ and $20^{\circ} \mathrm{N}$ is shown in Figs. $4 \mathrm{a}$ and $4 \mathrm{~b}$. The shaded regions in Fig. 4 denote the vertical wind anomalies. During the IOBM-no LNM cases, significant anomalous downward motions are observed to the west of $140^{\circ} \mathrm{E}$ (Fig. 4a), which is consistent with the results based on the OLR data displayed in Fig. 3a. The downward and westward wind anomalies observed in the lower-left corner of Fig. 4a suppressed the generation of TCs over the SCS. Obviously, during the IOBM-LNM cases (Fig. 4b), these situations were greatly enhanced; thus, an anomalous clockwise circulation can be readily observed. Compared with the IOBM-no LNM cases, the downward branch shifted eastward, and the center of downward motion was located over approximately $160^{\circ} \mathrm{E}$ at $500 \mathrm{hPa}$. Usually, TCs generated over the NWP originate from its southeastern quadrant (L. Wu et al. 2012). Hence, these enhanced anomalous downward motions influence the number and distribution of generated TCs.

We further examined the changes in the Hadley circulation over the NWP to show additional information, including the meridional motions (Figs. $4 \mathrm{c}$,d). Considering the results illustrated in Figs. $4 \mathrm{a}$ and $4 \mathrm{~b}$, our analysis focuses on the band of $130^{\circ} \mathrm{E}-180^{\circ}$. As shown in Fig. 4c, the boreal downward motions corresponding to the IOBM-no LNM cases were confined to the lower troposphere over approximately $20^{\circ} \mathrm{N}$. Significant signals from the Southern Hemisphere are also observed, although the influence of this component remains unclear. In contrast, during the IOBM-LNM cases, the downward motions gathered around the boreal tropics to the south of $25^{\circ} \mathrm{N}$, and significant southward motions are observed in the lower troposphere. This result can explain the enhancement of the anticyclonic anomaly and thus the suppression of TC genesis.

\section{Impact of La Niña Modoki on the changes in TC-related thermodynamic variables and energy conversions}

As mentioned above, La Niña Modoki can modulate the impacts of the warm IOBM cases, thereby producing an additional impact on the anomalous changes in atmospheric circulations raised by the IOBM-no LNM cases. Accordingly, we tried to further examine the changes in the thermodynamic variables favorable to the genesis of TCs and the associated barotropic eddy kinetic energy (EKE) conversions to help reveal the inner dynamics of the aforementioned processes. A large positive low-level relative vorticity can be observed in the MTs, leading to synoptic-scale lowlevel convergence and cumulus convection and thus TC genesis (Gray 1968; Zehnder 1991). The 850-hPa relative vorticity is usually used to represent the intensity and location of the MT (L. Wu et al. 2012), which can largely influence the interannual and interdecadal variations of TCs generated over the NWP. Therefore, the 850 -hPa relative vorticity is the most important dynamic forcing on TC genesis (Molinari and Vollaro 2012). As shown in Fig. 5a, during the 
(a)

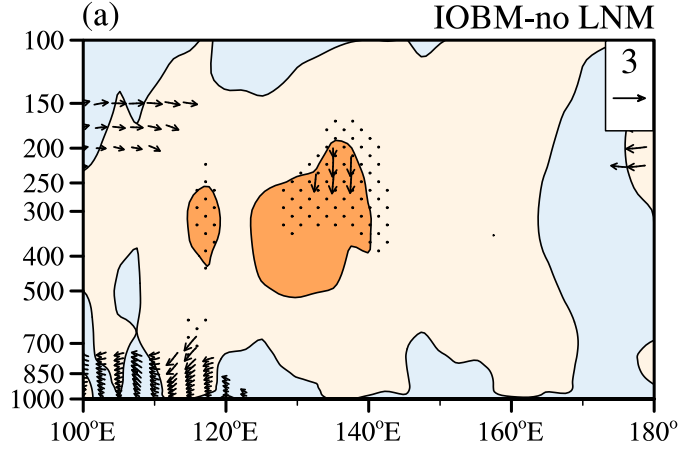

(c)

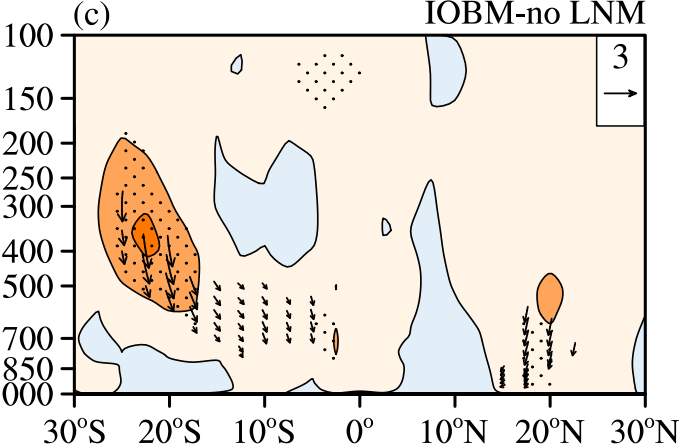

(b)

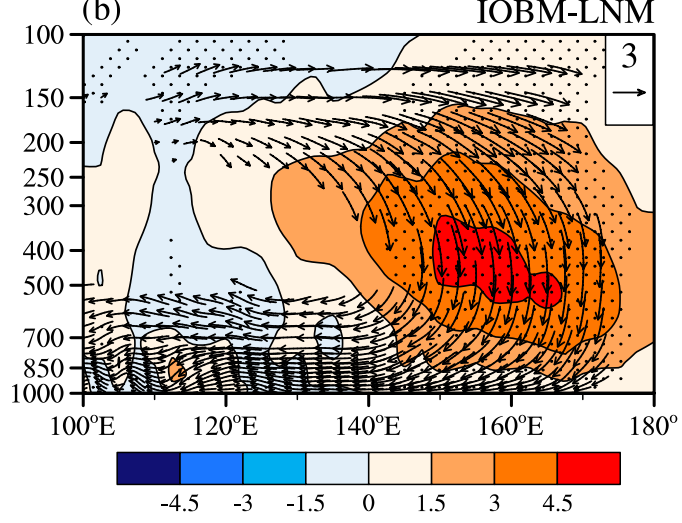

(d)

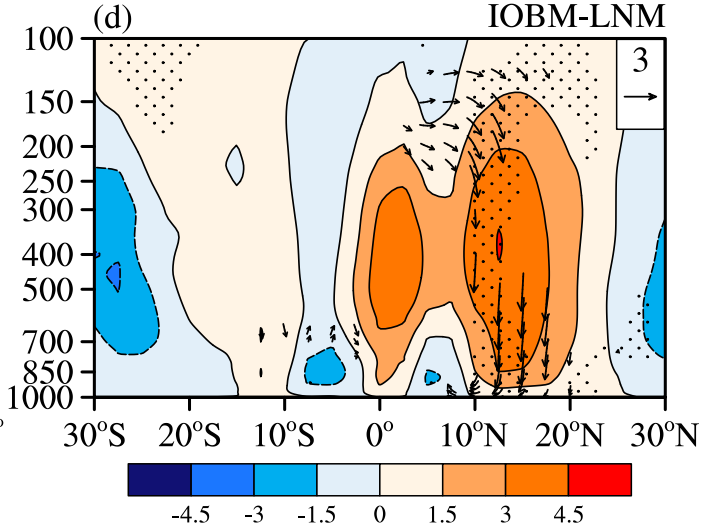

FIG. 4. Composite summer (JJA) mean zonal-vertical circulation anomalies averaged between $0^{\circ}$ and $20^{\circ} \mathrm{N}$ for the (a) IOBM-no LNM and (b) IOBM-LNM events and meridional circulation averaged between $130^{\circ} \mathrm{E}$ and $180^{\circ}$ for the (c) IOBM-no LNM and (d) IOBM-LNM events (vectors; $\mathrm{m} \mathrm{s}^{-1}$ for $u$ and $v ; 5 \times 10^{-3} \mathrm{~Pa} \mathrm{~s}^{-1}$ for $\omega$; shadings: vertical velocities). The vectors and stippling shown denote the anomalies significant at the $90 \%$ confidence level according to the Student's $t$ test.

IOBM-no LNM cases, negative relative vorticity anomalies are observed in the off-equatorial regions, suggesting the weakening of the northwestern part of the MT. However, the weakening over the southeastern NWP is not significant and even exhibits opposite signals. The influences of the IOBM-no LNM cases on the low-level relative vorticity and the MT are weak. In contrast, when La Niña Modoki becomes involved, the weakening of the low-level relative vorticity becomes greatly enhanced (Fig. 5b). The northwest-southeast negative anomalies lie in the regions of the MT, indicating that a significant influence can be induced in the IOBM-LNM cases. The weakening of the MT, especially its eastern component, leads to a decrease in TC genesis over this region. This result is also consistent with the distributions of TCs shown in Fig. $3 b$ characterized by fewer TCs generated to the east of $150^{\circ} \mathrm{E}$.

We further examined the changes in the upper-level divergence, which also constitutes an important dynamic environmental factor. This upper-level pumping or dumping can show positive feedback on low-level convergence and tropospheric convection. As shown in Fig. 6a, during the IOBM-no LNM cases, the distribution of the 200-hPa divergence anomalies shows a strong resemblance to the $850-\mathrm{hPa}$ relative vorticity anomalies shown in Fig. 5a. However, a significant southward shift of the negative signals is observed, indicating that the impact from upper-level divergence on lower-level systems will be somewhat diminished due to the misplaced coupling. Notably, the signals in the IOBM-LNM cases are different from those in the IOBM-no LNM cases (Fig. 6b): furthermore, the coverage and intensity of the negative $200-\mathrm{hPa}$ divergence anomalies are both enlarged in the IOBMLNM cases compared with the IOBM-no LNM cases. Concurrent with the enhanced $200-\mathrm{hPa}$ convergence, the low-level relative vorticity and convection will be suppressed.

In addition, the generation and development of TCs over the NWP are highly related to the $200-850-\mathrm{hPa}$ vertical wind shear (VWS) (Gray 1968). This environmental factor can reflect the stability of the atmosphere; that is, the environment is more favorable for TC genesis 

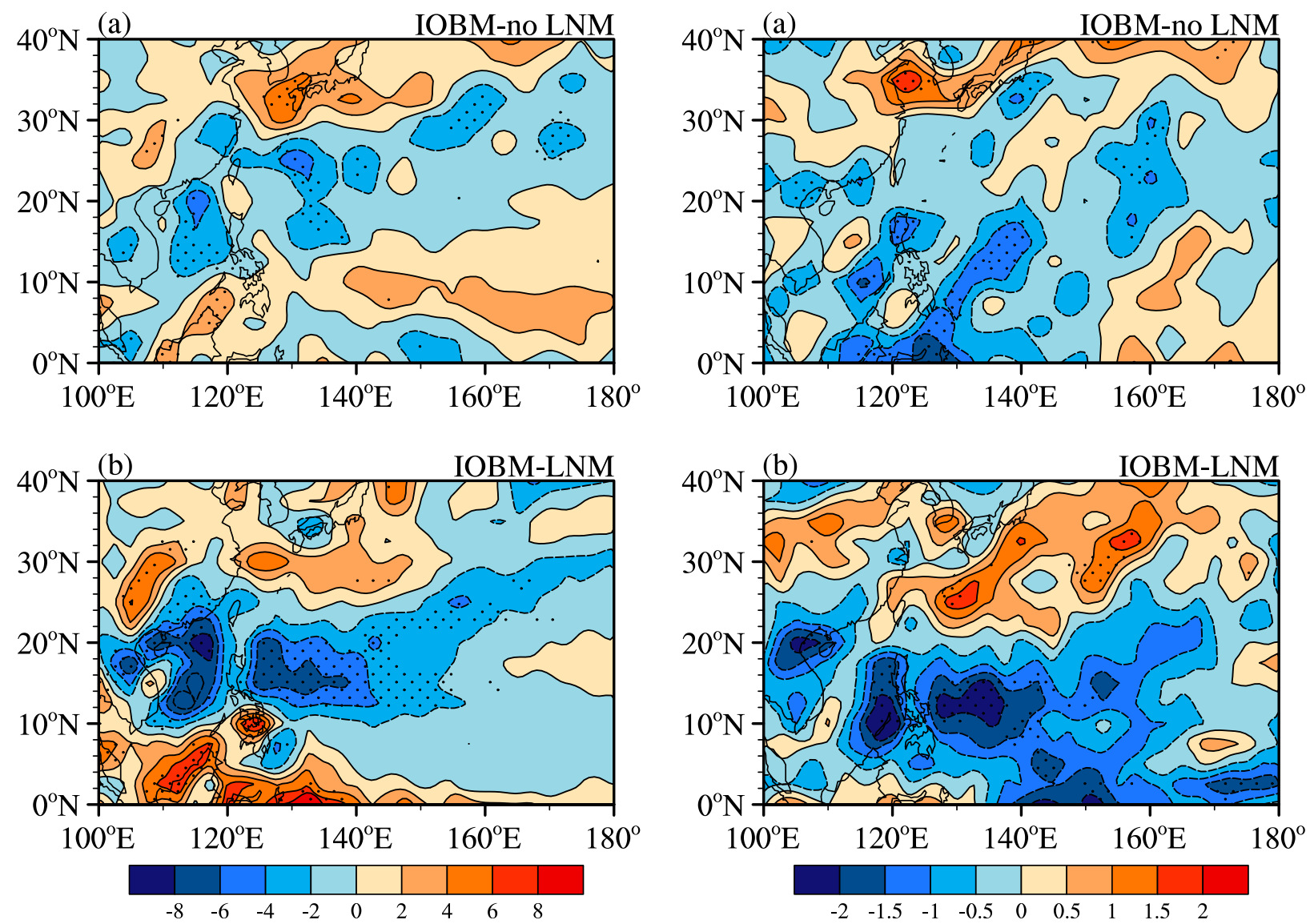

FIG. 5. Composite summer (JJA) mean 850 -hPa vorticity anomalies $\left(10^{-6} \mathrm{~s}^{-1}\right)$ for the (a) IOBM-no LNM and (b) IOBMLNM. Stippling denotes anomalies significant at the $90 \%$ confidence level according to the Student's $t$ test.

if the VWS is relatively weak. In this section, the VWS is calculated between the winds at 200 and $850 \mathrm{hPa}$, including both the horizontal zonal and the meridional winds (Feng et al. 2014). During the IOBM-no LNM cases, positive signals are found in the subtropical band between $20^{\circ}$ and $30^{\circ} \mathrm{N}$ (Fig. 7a). This region is consistent with the behavior of the 850 -hPa relative vorticity anomalies shown in Fig. 5a. Considering the mean location of the MT in JJA, the significant negative VWS anomalies in the tropics are not as influential as those in the off-equatorial regions. In contrast, the positive VWS anomalies are enhanced in the IOBM-LNM cases. Together with the aforementioned negative $850-\mathrm{hPa}$ relative vorticity anomalies and $200-\mathrm{hPa}$ anomalous convergence, this VWS provides a more unfavorable atmospheric configuration for TC genesis in JJA over the NWP.

Apart from the pure dynamic factors mentioned above, the midtropospheric $(500-700 \mathrm{hPa})$ moisture supply is also considered herein. The abundant moisture

FIG. 6. Composite summer (JJA) mean 200-hPa divergence anomalies $\left(10^{-6} \mathrm{~s}^{-1}\right)$ for the (a) IOBM-no LNM and (b) IOBMLNM. Stippling denotes anomalies significant at the $90 \%$ confidence level according to the Student's $t$ test.

supply induces latent heat release and helps in the formation of the warm core of TC, which is critical to TC genesis over the NWP. Because the TCs are generally steered westward, the water vapors from the eastern NWP are more influential on the generation of TCs. In the IOBM-no LNM cases, few water vapors can be provided for TC genesis (Fig. 8a) and negative anomalies show a somewhat uniform distribution over the NWP. In contrast, during the IOBM-LNM cases, the main reduction in the moisture supply is focused with a greater amplitude over the eastern NWP (Fig. 8b). These amplified negative anomalies can be attributed to the cold SST of La Niña Modoki over the CP. This result may further explain the reduced generation of TCs over the eastern NWP.

To reveal additional information regarding the inner dynamic processes of the modulation of the warm IOBM by La Niña Modoki, we calculated the barotropic EKE conversion, which is the main energy conversion process associated with TC genesis over 

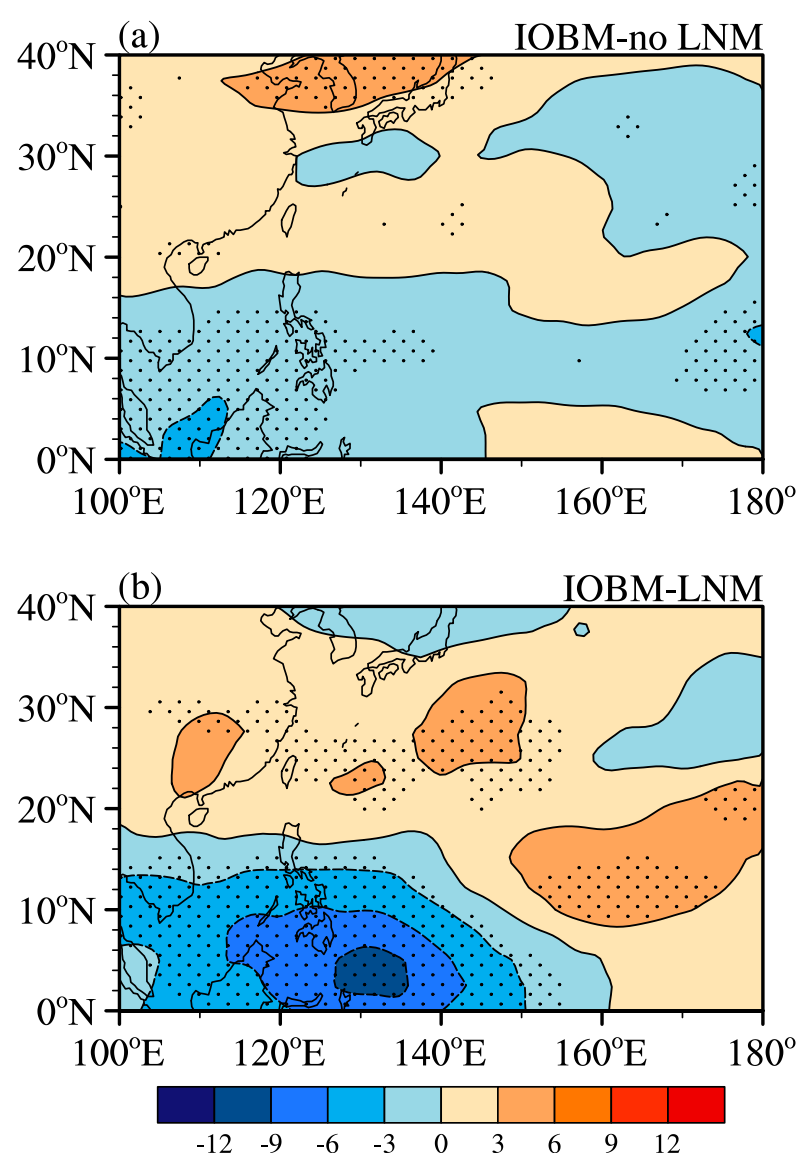

FIG. 7. Composite summer (JJA) mean 200-850-hPa VWS anomalies $\left(\mathrm{m} \mathrm{s}^{-1}\right)$ for the (a) IOBM-no LNM and (b) IOBMLNM. Stippling denotes anomalies significant at the $90 \%$ confidence level according to the Student's $t$ test.

the NWP (Ha et al. 2013a,b; Feng et al. 2014). This analysis separates the eddy from the mean flow, where the eddy represents the synoptic disturbances. Statistically, when the EKE increases, additional energy is transferred from the mean flow to the short-term disturbances. These disturbances can develop into TCs under appropriate environments. Following Maloney and Hartmann (2001), the equation for the barotropic EKE conversion is as follows:

$$
\frac{\partial}{\partial t} K_{\text {baro }}^{\prime}=-\overline{u^{\prime} v^{\prime}} \frac{\partial}{\partial \mathrm{y}} \bar{u}-\overline{u^{\prime} v^{\prime}} \frac{\partial}{\partial x} \bar{v}-\overline{u^{\prime 2}} \frac{\partial}{\partial x} \bar{u}-\overline{v^{\prime 2}} \frac{\partial}{\partial y} \bar{v} .
$$

In Eq. (2), $u$ denotes the horizontal zonal winds, $v$ represents the meridional winds, and $K$ denotes the kinetic energy, that is, $\left(u^{2}+v^{2}\right) / 2$. Here, $\bar{A}$ denotes the mean value of a variable, and $A^{\prime}$ stands for the anomalies. Parameter $K_{\text {baro }}^{\prime}$ on the left-hand side of Eq. (2) denotes the horizontal barotropic EKE, and
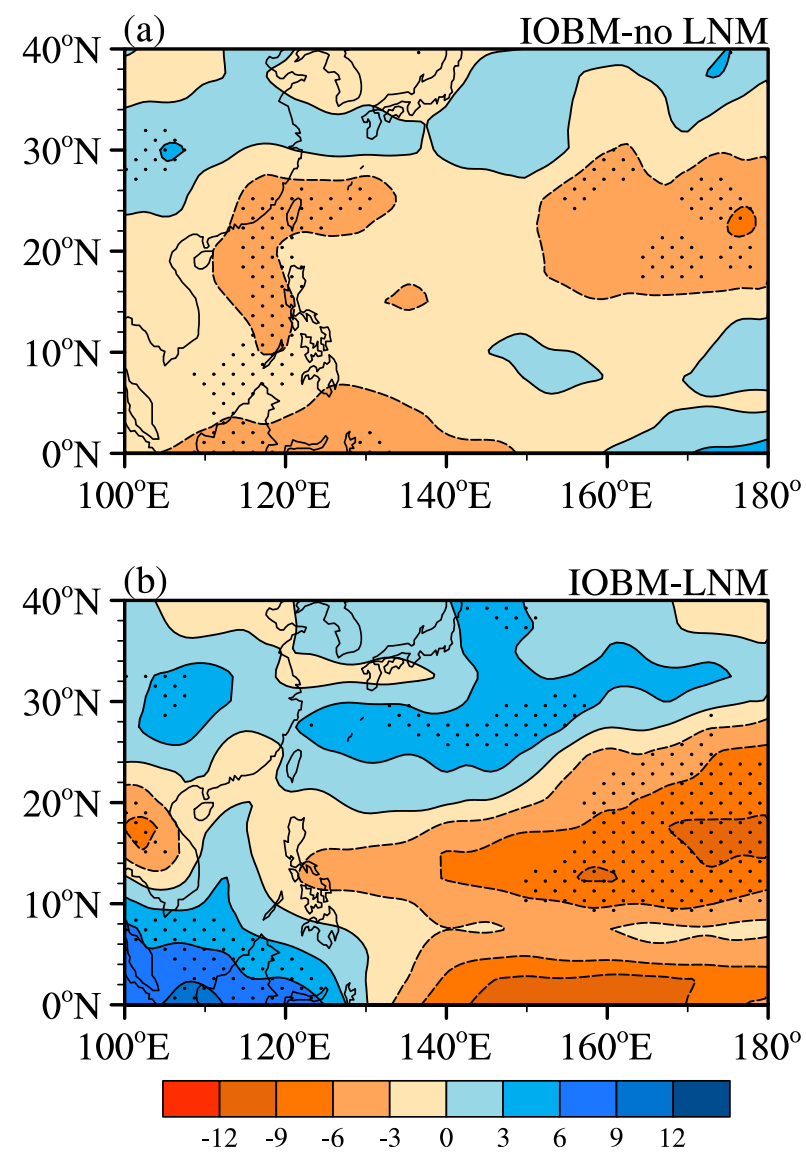

FIG. 8. Composite summer (JJA) mean 700-500-hPa relative humidity anomalies (\%) for the (a) IOBM-no LNM and (b) IOBM-LNM. Stippling denotes anomalies significant at the $90 \%$ confidence level according to the Student's $t$ test.

$\partial / \partial t$ indicates its tendency. That is, when this tendency increases, the EKE will receive more energy from the mean flow, and vice versa. A greater EKE tendency means more of the mean flow will break into synoptic disturbances, providing additional initial disturbances that will facilitate the genesis of TCs. We observed an insignificant weak EKE tendency in the tropics during the IOBM-no LNM cases (Fig. 9a), indicating that the influences of the IOBM-no LNM cases on the energy conversion are relatively limited. In contrast, the IOBM-LNM cases produce a more suppressed EKE conversion in the band between $10^{\circ}$ and $20^{\circ} \mathrm{N}$ (Fig. 9b). The negative anomalies follow the MT regions over the NWP, providing fewer seedlings for TC genesis. The stippling shown in Fig. 9b is superimposed onto the eastern part of the NWP to explain the inner dynamics of the decrease in the genesis of TCs therein.

These results suggest that an anticyclonic anomaly to the south of $30^{\circ} \mathrm{N}$ and a cyclonic anomaly to the north of 

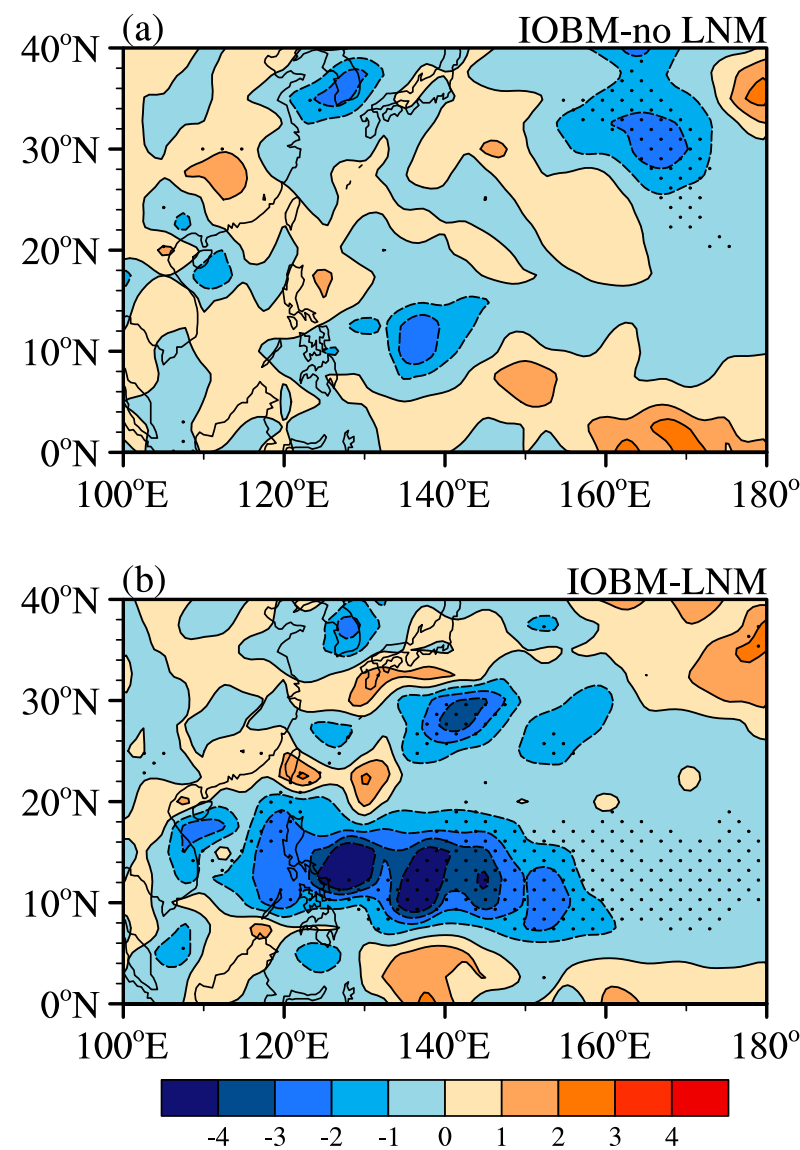

FIG. 9. Composite summer (JJA) mean barotropic EKE tendencies at $850-\mathrm{hPa}$ anomalies $\left(10^{-5} \mathrm{~m}^{2} \mathrm{~s}^{-3}\right)$ for the (a) IOBM-no LNM and (b) IOBM-LNM. Stippling denotes anomalies significant at the $90 \%$ confidence level according to the Student's $t$ test.

$30^{\circ} \mathrm{N}$ are responsible for the further suppression of TC genesis in the NWP modulated by the additional impacts of La Niña Modoki, thus implying that a specific circulation pattern was responsible for the contrasts. Therefore, we investigated the interannual variations of the Pacific-Japan (PJ) pattern, or East Asia-Pacific pattern (EAP), which is normally a leading pattern of 850-hPa relative vorticity and circulation anomalies in boreal summertime (Huang 2004; Kosaka et al. 2013). Following Kosaka et al. (2013), we performed an EOF analysis of relative vorticity on the $850-\mathrm{hPa}$ level to extract the first dominant mode (EOF1) of variability and its principal component (PC1) over the summer NWP. As shown in Fig. 10a, the 850-hPa relative vorticity and zonal and meridional wind anomalies are regressed onto the normalized time series of PC1. The $\mathrm{PJ} / \mathrm{EAP}$ wave train is observed clearly, with $30^{\circ} \mathrm{N}$ serving as the border between the midlatitudes and tropics. Compared with the positive values in the IOBM-LNM cases (blue bars in Fig. 10b), the values
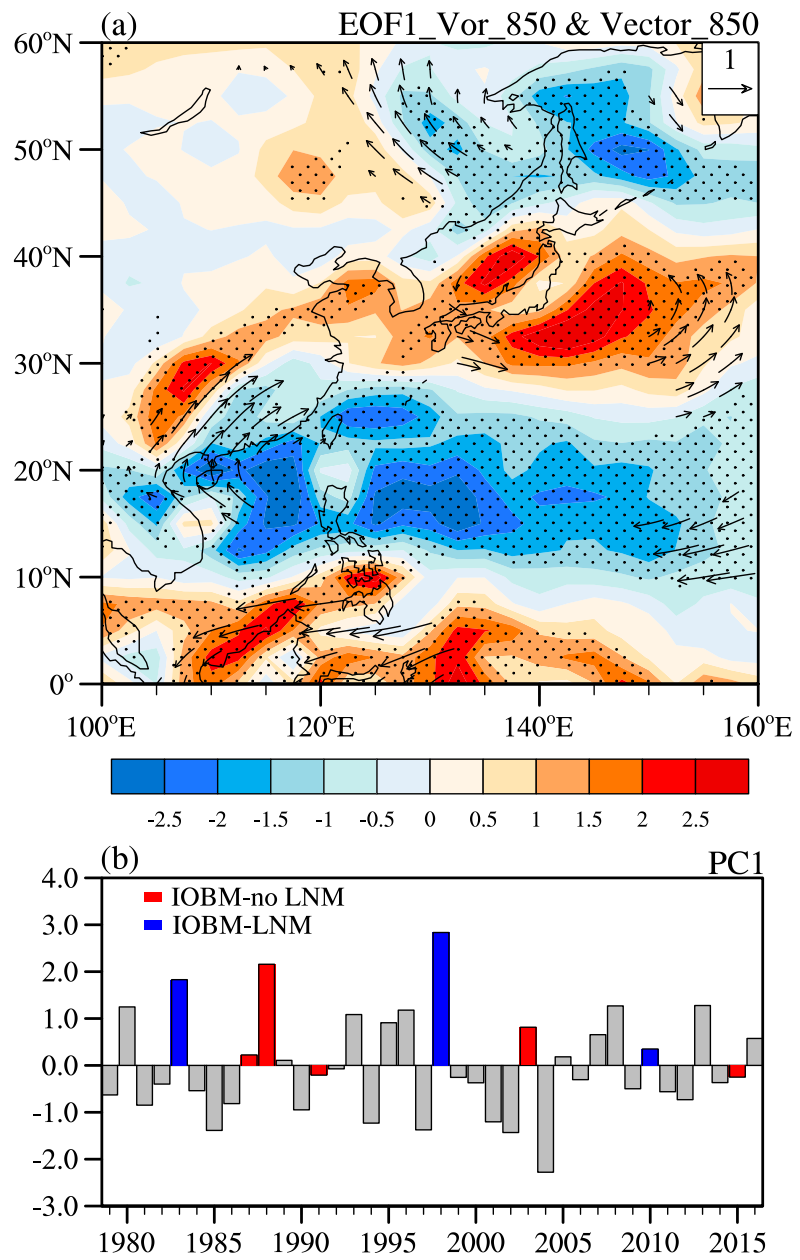

FIG. 10. (a) First leading EOF mode of 850-hPa relative vorticity anomalies $\left(10^{-6} \mathrm{~s}^{-1}\right)$ during JJA based on the period from 1979 to 2016. The vectors and stippling shown denote the anomalies significant at the $90 \%$ confidence level according to the Student's $t$ test. (b) Time series of PC1 (bars).

in the IOBM-no LNM cases (red bars in Fig. 10b) are negative in certain years (1991 and 2015). Hence, the contrasts in the two cases can be attributed to the enhancement of the southern component of the PJ/EAP pattern in the IOBM-LNM cases relative to the IOBMno LNM cases. As shown in Figs. $2 a$ and $2 b$, the main difference in the SSTAs between the two cases is the superimposed La Niña Modoki-like SST anomalies in the IOBM-LNM cases. These SSTAs change the SST gradient between the Indian Ocean and the NWP, which may lead to a change in the PJ/EAP pattern.

\section{Summary and discussion}

Previous studies have revealed the influence of warm IOBM events on the genesis of TCs over the NWP in JJA (Tao et al. 2012). Xie et al. (2009) believed that 
El Niño-related warming could charge the TIO in the early spring with a subsequent discharge in the following summer. This process could maintain anomalous anticyclones and lead to the suppression of TC genesis (Du et al. 2011). However, in the present study, we notice that a high percentage of warm IOBM cases are coincident with La Niña Modoki, which could play important roles in affecting the genesis of TCs over the NWP. Therefore, we divided warm IOBM cases into two groups: the IOBM-no LNM and IOBMLNM cases.

Based on the composite analyses, we first compared the influences of these two groups on the boreal summertime atmospheric circulations. The results show that the convections were significantly suppressed to the west of $140^{\circ} \mathrm{E}$ during the IOBM-no LNM cases, with anomalous anticyclonic low-level winds observed over the western part of the NWP. These anomalous downward motions were focused within the low-level troposphere over the southwestern NWP. The annual number of generated TCs decreased slightly compared with the climatological mean. In contrast, during the IOBM-LNM cases, weaker convections were observed over the tropics, and the anticyclonic wind anomalies were strengthened significantly. Compared with the IOBM-no LNM cases, the downward branch of the northern Walker circulation shifted eastward with an enhanced center located approximately $160^{\circ} \mathrm{E}$ at $500 \mathrm{hPa}$. Obviously, under the modulation of $\mathrm{La}$ Niña Modoki, the impacts of warm IOBM cases on the summertime atmospheric circulations were substantially enhanced.

We further examined the changes in TC-related thermodynamic variables. During the IOBM-no LNM cases, insignificant negative relative vorticity anomalies were observed in the off-equatorial regions, indicating that the influences of the IOBM-no LNM cases on the MT are weak. In addition, our study shows the existence of a misplaced atmospheric configuration because the 200-hPa enhanced convergence was shifted toward the south. The distribution of the 850-200-hPa VWS also exhibited weak feedback with an insignificant positive band observed over the subtropics. However, under the modulation of La Niña Modoki, the weakening of the low-level relative vorticity was largely enhanced over the MT. The enhanced 200-hPa convergence helped suppress the lowlevel relative vorticity and convection. Additionally, the enlarged positive VWS anomalies restricted convective activities. Together with the poor moisture supply from the eastern NWP, the IOBM-LNM cases provided more unfavorable atmospheric conditions for TC genesis.
In addition, we analyzed the changes in the barotropic EKE, thereby revealing the atmospheric capacity to provide initial disturbances that facilitate the genesis of TCs. We observed insignificant changes in the EKE tendency during the IOBM-no LNM cases: in sharp contrast, the IOBM-LNM cases produce a greater suppression of EKE conversion over the MT regions, thereby suppressing TC genesis by providing fewer initial disturbances. To investigate the underlying circulation pattern responsible for the contrasts, we examined the interannual variations of the PJ/EAP pattern. The results showed that the southern component of the PJ/EAP pattern is stronger in IOBMLNM cases than in the IOBM-no LNM cases, which explains the atmospheric cause of the modulation by La Niña Modoki.

Ha et al. (2015) examined the contribution of EIO SSTAs to TC activity under different ENSO phases, and they suggested that these SSTAs play a secondary role in TC genesis compared to ENSO. However, according to previous work (e.g., Xie et al. 2009) and the results shown in Fig. 1, the influence of the Indian Ocean is the primary mechanism during boreal summer. Hence, the present work showed that the modulation of La Niña Modoki is a secondary modulation.

It is not proper to use a simple index to define real phenomenon. The warm IOBM cases defined in this study are mainly selected by a threshold of 0.5 standard deviation of the interannual TIO-averaged SSTA. This threshold aims to select consistent basinwide warming cases in the TIO. It is inevitable that this selection may involve other signals. In the selected warm IOBM cases, although the IOBM signal in 1991 was slightly weaker than the IOD mode signal, warming over the TIO is significant. Hence, as a group, the year 1991 can be classified into warm IOBM cases and used to study the influence from TIO warming conditions. As shown in Fig. 11, the summertime SSTA patterns in all warm IOBM cases show the actual marine thermal situation over the Indian Ocean. The detrended SSTA patterns showed similar distributions (not shown).

Zhang et al. (2015) and Ding et al. (2017) analyzed the spatial distribution of SSTAs over the tropical Pacific Ocean to distinguish two types of La Niña events, which is a more direct method to select La Niña Modoki events. They defined a La Niña Modoki case as having a negative SSTA center primarily located west of $150^{\circ} \mathrm{W}$, which is the boundary between the Niño-3 and Niño-4 areas. Therefore, we further examined all SSTA distributions in the five selected "La Niña Modoki" cases to determine whether they were chosen correctly. Cold tongues extended westward in these years (Fig. 12). We compared the values 

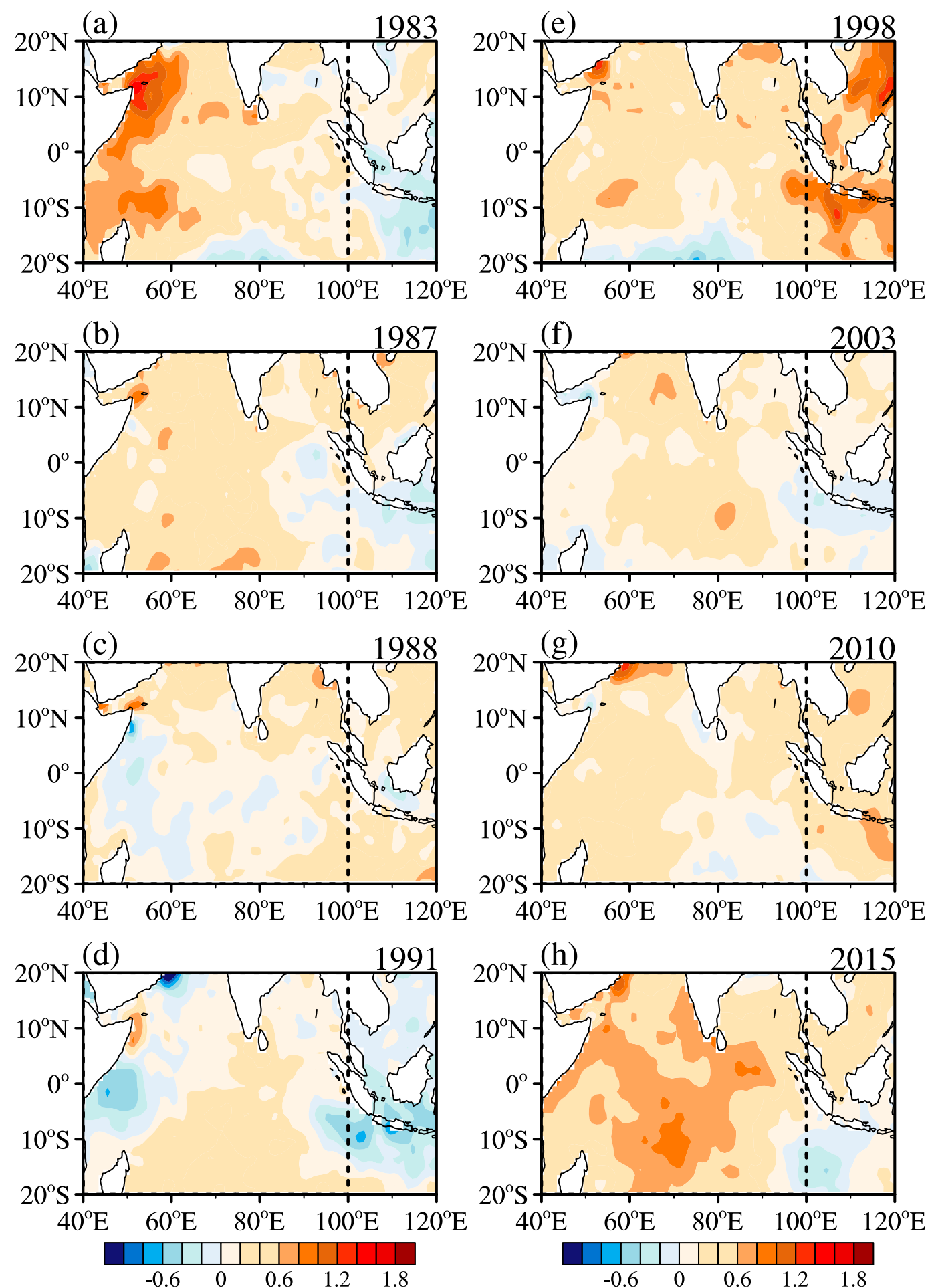

FIG. 11. SST (K) anomalies in (a) 1983, (b) 1987, (c) 1988, (d) 1991, (e) 1998, (f) 2003, (g) 2010, and (h) 2015. The black boxes in (a)-(h) denote the key areas of the IOBM mode. 

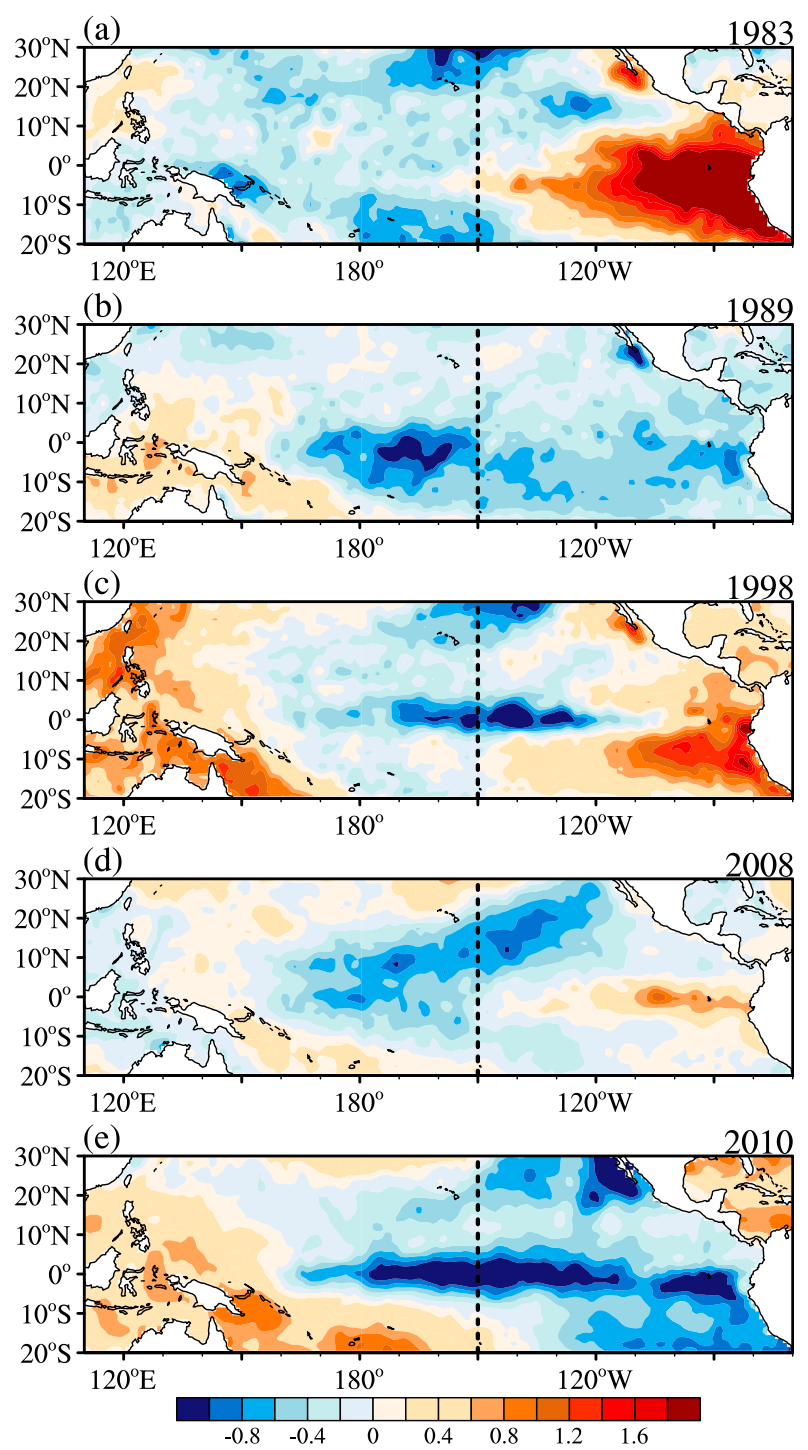

FIG. 12. SST (K) anomalies in (a) 1983, (b) 1989, (c) 1998, (d) 2008, and (c) 2010 . The black lines in (a)-(e) denote $150^{\circ} \mathrm{W}$.

of the EMI and Niño-3 index in these years, and all five years showed a greater amplitude in the EMI than that of the Niño-3 index, which is usually used to define conventional ENSO cases. Therefore, it is appropriate to identify these years as La Niña Modoki cases.

Numerical experiments with additional cases based on the present study should be performed in the near future. In addition, sensitivity tests should be carried out while searching for the key regions of SSTAs that have introduced the substantial changes in the modulation discussed in this study.

Acknowledgments. This work was supported by the National Key Research and Development Program of China (2018YFC1506003) and the National Natural
Science Foundation of China (Grant 41705071, 41661144016, and 41461164005). The authors thank Dr. Yao Ha for his helpful comments on an earlier version of the manuscript. The authors are grateful for the comments and suggestions provided by the editor and five anonymous reviewers.

\section{REFERENCES}

Ashok, K., S. K. Behera, S. A. Rao, H. Weng, and T. Yamagata, 2007: El Niño Modoki and its possible teleconnection. J. Geophys. Res., 112, C11007, https://doi.org/10.1029/2006JC003798.

Cai, W., and T. Cowan, 2009: La Niña Modoki impacts Australia autumn rainfall variability. Geophys. Res. Lett., 36, L02706, https://doi.org/10.1029/2008GL036443.

Chen, G., and C.-Y. Tam, 2010: Different impacts of two kinds of Pacific Ocean warming on tropical cyclone frequency over the western North Pacific. Geophys. Res. Lett., 37, L01803, https:// doi.org/10.1029/2009GL041708.

Ding, S., W. Chen, J. Feng, and H.-F. Graf, 2017: Combined impacts of PDO and two types of La Niña on climate anomalies in Europe. J. Climate, 30, 3253-3278, https://doi.org/10.1175/JCLI-D-16-0376.1.

Du, Y., L. Yang, and S.-P. Xie, 2011: Tropical Indian Ocean influence on northwest Pacific tropical cyclones in summer following strong El Niño. J. Climate, 24, 315-322, https://doi.org/ 10.1175/2010JCLI3890.1.

Feng, J., and W. Chen, 2014: Influence of the IOD on the relationship between El Niño Modoki and the East Asianwestern North Pacific summer monsoon. Int. J. Climatol., 34, 1729-1736, https://doi.org/10.1002/joc.3790.

— - C. Y. Tam, and W. Zhou, 2011: Different impacts of El Niño and El Niño Modoki on China rainfall in the decaying phases. Int. J. Climatol., 31, 2091-2101, https://doi.org/10.1002/joc.2217.

,-- , and Y. Li, 2017: Asymmetry of the winter extra-tropical teleconnections in the Northern Hemisphere associated with two types of ENSO. Climate Dyn., 48, 2135-2151, https:// doi.org/10.1007/s00382-016-3196-2.

Feng, T., G.-H. Chen, R.-H. Huang, and X.-Y. Shen, 2014: Largescale circulation patterns favourable to tropical cyclogenesis over the western North Pacific and associated barotropic energy conversions. Int. J. Climatol., 34, 216-227, https://doi.org/ 10.1002/joc.3680.

Frauen, C., D. Dommenget, N. Tyrrell, M. Rezny, and S. Wales, 2014: Analysis of the nonlinearity of El Niño-Southern Oscillation teleconnections. J. Climate, 27, 6225-6244, https:// doi.org/10.1175/JCLI-D-13-00757.1.

Gray, W. M., 1968: Global view of the origin of tropical disturbances and storms. Mon. Wea. Rev., 96, 669-700, https://doi.org/ 10.1175/1520-0493(1968)096<0669:GVOTOO > 2.0.CO;2.

Ha, Y., Z. Zhong, Y. Hu, and X. Yang, 2013a: Influences of ENSO on western North Pacific tropical cyclone kinetic energy and its meridional transport. J. Climate, 26, 322-332, https:// doi.org/10.1175/JCLI-D-11-00543.1.

,,-- Y. Zhu, and Y. Hu, 2013b: Contributions of barotropic energy conversion to Northwest Pacific tropical cyclone activity during ENSO. Mon. Wea. Rev., 141, 1337-1346, https:// doi.org/10.1175/MWR-D-12-00084.1.

- _ - X. Yang, and Y. Sun, 2015: Contribution of East Indian Ocean SSTA to Western North Pacific tropical cyclone activity under El Niño/La Niña conditions. Int. J. Climatol., 35, 506-519, https://doi.org/10.1002/joc.3997. 
Huang, G., 2004: An index measuring the interannual variation of the East Asian summer monsoon-The EAP index. $A d v$. Atmos. Sci., 21, 41-52, https://doi.org/10.1007/BF02915679.

Huang, R., and Y. Wu, 1989: The influence of ENSO on the summer climate change in China and its mechanism. Adv. Atmos. Sci., 6, 21-32, https://doi.org/10.1007/BF02656915.

_- W. Chen, B. L. Yang, and R. H. Zhang, 2004: Recent advances in studies of the interaction between the east Asian winter and summer monsoons and ENSO cycle. Adv. Atmos. Sci., 21, 407-424, https://doi.org/10.1007/BF02915568.

Huangfu, J., R. Huang, and W. Chen, 2017a: Relationship between the South China Sea summer monsoon onset and tropical cyclone genesis over the western North Pacific. Int. J. Climatol., 37, 5206-5210, https://doi.org/10.1002/joc.5141.

,-- , and $-2017 \mathrm{~b}$ : Interdecadal increase of tropical cyclone genesis frequency over the western north Pacific in May. Int. J. Climatol., 37, 1127-1130, https://doi.org/10.1002/joc.4760.

, T. Feng, and L. Wu, 2017c: Interdecadal variation of tropical cyclone genesis and its relationship to the monsoon trough over the western North Pacific. Int. J. Climatol., 37, 3587-3596, https://doi.org/10.1002/joc.4939.

,,,--- and,- 2018 : Causes of the active typhoon season in 2016 following a strong El Niño with a comparison to 1998. Int. J. Climatol., 38, e1107-e1118, https://doi.org/ 10.1002/joc.5437.

Karori, M. A., J. Li, and F.-F. Jin, 2013: The asymmetric influence of the two types of El Niño and La Niña on summer rainfall over southeast China. J. Climate, 26, 4567-4582, https:// doi.org/10.1175/JCLI-D-12-00324.1.

Klein, S. A., B. J. Soden, and N.-C. Lau, 1999: Remote sea surface temperature variations during ENSO: Evidence for a tropical atmospheric bridge. J. Climate, 12, 917-932, https://doi.org/ 10.1175/1520-0442(1999)012<0917:RSSTVD>2.0.CO;2.

Knapp, K. R., M. C. Kruk, D. H. Levinson, H. J. Diamond, and C. J. Neumann, 2010: The International Best Track Archive for Climate Stewardship (IBTrACS) unifying tropical cyclone data. Bull. Amer. Meteor. Soc., 91, 363-376, https://doi.org/ 10.1175/2009BAMS2755.1.

Kosaka, Y., S.-P. Xie, N.-C. Lau, and G. A. Vecchi, 2013: Origin of seasonal predictability for summer climate over the Northwestern Pacific. Proc. Natl. Acad. Sci. USA, 110, 7574-7579, https://doi.org/10.1073/pnas.1215582110.

Li, R. C. Y., and W. Zhou, 2012: Changes in western Pacific tropical cyclones associated with the El Niño-Southern Oscillation cycle. J. Climate, 25, 5864-5878, https://doi.org/ 10.1175/JCLI-D-11-00430.1.

Liebmann, B., and C. A. Smith, 1996: Description of a complete (interpolated) outgoing longwave radiation dataset. Bull. Amer. Meteor. Soc., 77, 1275-1277, https://doi.org/10.1175/ 1520-0477-77.6.1274.

Maloney, E. D., and D. L. Hartmann, 2001: The Madden-Julian oscillation, barotropic dynamics, and North Pacific tropical cyclone formation. Part I: Observations. J. Atmos. Sci., 58, 2545-2558, https://doi.org/10.1175/1520-0469(2001)058<2545: TMJOBD $>2.0 . \mathrm{CO} ; 2$.

Molinari, J., and D. Vollaro, 2012: A subtropical cyclonic gyre associated with interactions of the MJO and the midlatitude jet. Mon. Wea. Rev., 140, 343-357, https://doi.org/ 10.1175/MWR-D-11-00049.1.

Rayner, N., and Coauthors, 2003: Global analyses of sea surface temperature, sea ice, and night marine air temperature since the late nineteenth century. J. Geophys. Res., 108, 4407, https://doi.org/10.1029/2002JD002670.
Saji, N., B. Goswami, P. Vinayachandran, and T. Yamagata, 1999: A dipole mode in the tropical Indian Ocean. Nature, 401, 360 363, http://doi.org/10.1038/43854.

Simmons, A., S. Uppala, D. Dee, and S. Kobayashi, 2007: ERAInterim: New ECMWF reanalysis products from 1989 onwards. ECMWF Newsletter, No. 110, ECMWF, Reading, United Kingdom, 25-35, https://www.ecmwf.int/sites/default/ files/elibrary/2006/14615-newsletter-no110-winter-200607.pdf.

Song, L., S. Chen, W. Chen, and X. Chen, 2017: Distinct impacts of two types of La Niña events on Australian summer rainfall. Int. J. Climatol., 37, 2532-2544, https://doi.org/ 10.1002/joc. 4863 .

Tao, L., L. Wu, Y. Wang, and J. Yang, 2012: Influence of tropical Indian Ocean warming and ENSO on tropical cyclone activity over the western North Pacific. J. Meteor. Soc. Japan, 90, 127144, https://doi.org/10.2151/jmsj.2012-107.

Wang, B., R. Wu, and X. Fu, 2000: Pacific-East Asian teleconnection: How does ENSO affect East Asian climate? J. Climate, 13, 1517-1536, https://doi.org/10.1175/ 1520-0442(2000)013<1517:PEATHD>2.0.CO;2.

Wang, X., D. Wang, W. Zhou, and C. Li, 2012: Interdecadal modulation of the influence of La Niña events on mei-yu rainfall over the Yangtze River valley. Adv. Atmos. Sci., 29, 157-168, https://doi.org/10.1007/s00376-011-1021-8.

Weng, H., G. Wu, Y. Liu, S. K. Behera, and T. Yamagata, 2011: Anomalous summer climate in China influenced by the tropical Indo-Pacific Oceans. Climate Dyn., 36, 769-782, https:// doi.org/10.1007/s00382-009-0658-9.

$\mathrm{Wu}, \mathrm{B}$., T. Li, and T. Zhou, 2010: Relative contributions of the Indian Ocean and local SST anomalies to the maintenance of the western North Pacific anomalous anticyclone during the El Niño decaying summer. J. Climate, 23, 2974-2986, https:// doi.org/10.1175/2010JCLI3300.1.

— T. Thou, and T. Li, 2012: Two distinct modes of tropical Indian Ocean precipitation in boreal winter and their impacts on equatorial western Pacific. J. Climate, 25, 921-938, https:// doi.org/10.1175/JCLI-D-11-00065.1.

Wu, L., Z. Wen, R. Huang, and R. Wu, 2012: Possible linkage between the monsoon trough variability and the tropical cyclone activity over the western North Pacific. Mon. Wea. Rev., 140, 140-150, https://doi.org/10.1175/MWR-D-11-00078.1.

Xie, S.-P., K. Hu, J. Hafner, H. Tokinaga, Y. Du, G. Huang, and T. Sampe, 2009: Indian Ocean capacitor effect on Indo-Western Pacific climate during the summer following El Niño. J. Climate, 22, 730-747, https://doi.org/10.1175/2008JCLI2544.1.

Yu, J., C. Chen, T. Li, X. Zhao, H. Xue, and Q. Sun, 2016: Contribution of major SSTA modes to the climate variability of tropical cyclone genesis frequency over the western North Pacific. Quart. J. Roy. Meteor. Soc., 142, 1171-1181, https:// doi.org/10.1002/qj.2722.

Yuan, Y., and S. Yang, 2012: Impacts of different types of El Niño on the East Asian climate: Focus on ENSO cycles. J. Climate, 25, 7702-7722, https://doi.org/10.1175/JCLI-D-11-00576.1.

- W. Zhou, J. C. L. Chan, and C. Li, 2008a: Impacts of the basin-wide Indian Ocean SSTA on the South China Sea summer monsoon onset. Int. J. Climatol., 28, 1579-1587, https://doi.org/10.1002/joc.1671.

- , H. Yang, W. Zhou, and C. Li, 2008b: Influences of the Indian Ocean dipole on the Asian summer monsoon in the following year. Int. J. Climatol., 28, 1849-1859, https:// doi.org/10.1002/joc.1678.

Zehnder, J. A., 1991: The interaction of planetary-scale tropical easterly waves with topography: A mechanism for 
the initiation of tropical cyclones. J. Atmos. Sci., 48, 1217-1230, https://doi.org/10.1175/1520-0469(1991)048<1217: TIOPST $>2.0$.CO;2.

Zhan, R., Y. Wang, and X.-T. Lei, 2011a: Contributions of ENSO and East Indian Ocean SSTA to the interannual variability of northwest Pacific tropical cyclone frequency. J. Climate, 24, 509-521, https://doi.org/10.1175/ 2010JCLI3808.1.

_,- , and C.-C. Wu, 2011b: Impact of SSTA in East Indian Ocean on the frequency of Northwest Pacific tropical cyclones: A regional atmospheric model study. J. Climate, 24, 6227-6242, https://doi.org/10.1175/JCLI-D-10-05014.1. , and L. Tao, 2014: Intensified impact of East Indian Ocean SST anomaly on tropical cyclone genesis frequency over the western North Pacific. J. Climate, 27, 8724-8739, https://doi.org/10.1175/JCLI-D-14-00119.1.

Zhang, W., L. Wang, B. Xiang, L. Qi, and J. He, 2015: Impacts of two types of La Niña on the NAO during boreal winter. Climate Dyn., 44, 1351-1366, https://doi.org/10.1007/ s00382-014-2155-z. 